\title{
El diálogo que se encamina. La traducción entre Paul Celan y Doris Salcedo*
}

\author{
Ángela María Lopera Molano**
}

Recibido: 15 de marzo de 2015

Evaluado: 17 de abril de 2015

Aceptado: 22 de abril de 2015

\section{RESUMEN}

La obra de la artista colombiana Doris Salcedo establece un diálogo permanente con la obra poética de Paul Celan. Este diálogo se realiza a partir de la traducción artística de la poesía de Celan a las esculturas de Salcedo. Por tratarse de dos lenguajes del arte, esta traducción debe pasar por un proceso específico a partir de los conceptos de experiencia, desplazamiento, exilio y transposición, que se encuentran tanto en la poesía como en la escultura de estos artistas. La traducción es un diálogo constante y abierto sobre los temas más relevantes de la historia humana, en este caso, de la violencia, la guerra y las víctimas. Así como Paul Celan fue testigo en la Segunda Guerra Mundial, Doris Salcedo lo es del relato de las víctimas del conflicto armado en Colombia. A partir de la traducción se logra un diálogo, es decir, establecer un lugar de encuentro del arte y su historia con la realidad del país, y la posibilidad de activar la memoria colectiva.

Palabras clave: escultura, poesía, traducción, diálogo.

Artículo de reflexión basado en la tesis de maestría en Esthétique de la Université Paris 1 Panthéon-Sorbonne en 2010 titulada Dialogue qui chemine: la traduction entre Paul Celan et Doris Salcedo. Cómo citar este artículo: Lopera Molano, A.M. (2015). El diálogo que se encamina. La traducción entre Paul Celan y Doris Salcedo. Hallazgos, 12(24), 31-48 (doi: http://dx.doi.org/10.15332/s1794-3841.2015.0024.02).

* Magíster en Esthétique de la Université Paris 1 Panthéon-Sorbonne (Francia). Docente y directora del programa de Comunicación Social y Periodismo, Universidad de Ibagué (Colombia). Investigadora del grupo Rastro Urbano. Correo electrónico: angela.lopera@unibague.edu.co 


\section{Path drawing dialogue.Translation between Paul Celan and Doris Salcedo}

\section{Abstract}

The work of the Colombian artist Doris Salcedo establishes an ongoing dialogue with the poetry of Paul Celan. This dialogue

Salcedo's sculptures. Being two languages of art, this translation must go through a specific process which is based on the concepts of experience, displacement, exile and transposition, concepts present both in the poetry and the sculpture of these artists. Translation is then a constant and open dialogue about the most important issues of human history, being in this case, violence, war and victims. Just as Paul Celan was a witness during World War II; Doris Salcedo is a witness of the story of victims of armed conflict in Colombia. From translation dialogue is achieved, meaning the stablishment of a meeting place for art, its history, the country's reality and also the possibility of activating the collective memory.

Keywords: Sculpture, poetry, translation, dialogue. 


\section{O dialogo que se encaminha. A tradução entre Paul Celan e Dóris Salcedo}

Recebido: 15 de março de 2015

Avaliado: 17 de abril de 2015 Aceito: 22 de abril de 2015

\section{Resumo}

A obra da artista colombiana Dóris Salcedo estabelece um diálogo permanente com a obra poética do Paul Celan. Este diálogo realiza-se a partir da tradução artística da poesia do Celan nas esculturas de Salcedo. Por tratar-se de duas linguagens da arte, esta tradução deve passar por um processo específico a partir dos conceptos de experiência, deslocamento, exílio e transposição, que se encontram tanto na poesia como na escultura destes artistas. A tradução é um diálogo constante e aberto sobre os temas mais relevantes da história humana, neste caso, da violência, da guerra e das vitimas. Assim como Paul Celam foi testemunha da Segunda Guerra Mundial, Dóris Salcedo é testemunha do relato das vitimas do conflito armado na Colômbia. A partir da tradução logra-se um diálogo, aliás, estabelecer um lugar de encontro da arte e a sua história com a realidade do país e a possibilidade de ativar a memória coletiva.

Palavras-chave: escultura, poesia, tradução, diálogo. 
La traducción, en cambio, parece destinada a ilustrar la discusión estética.

Jorge Luis Borges.

\section{Presentación}

En 1932, en Las versiones homéricas, Jorge Luis Borges escribía que la dificultad de distinguir en una obra literaria eso que pertenecía al poeta y eso que pertenecía a la lengua es la misma dificultad a la que le debemos la posibilidad de tantas traducciones de La Odisea, todas auténticas y divergentes. Años antes, en 1923 Walter Benjamin escribió en el ensayo titulado "La tarea del traductor" que el error fundamental del traductor era conservar su propia lengua en vez de someterla a la fuerza y el poder de la lengua extranjera, porque la finalidad de la traducción consiste en expresar la relación entre las lenguas, resaltar las mutaciones del lenguaje, la época de un autor y la subjetividad de diferentes generaciones. Si Benjamin veía en la traducción una posibilidad de alargar y profundizar la lengua y de buscar lo esencial de aquellas mutaciones, Borges va más allá de esto y afirma que la traducción, en vez de ocultar la creación estética, comienza a ilustrarla.

El diálogo que se plantea entre el poeta Paul Celan (1920-1970) y la artista colombiana Doris Salcedo (nacida en 1958) pone en evidencia esta idea de la traducción. Se va a abordar, en primer lugar, cómo puede realizarse una traducción entre dos lenguas no-naturales como la poesía de Paul Celan y la escultura de Doris Salcedo. En segundo lugar, se hará una descripción de la traducción como un diálogo que se encamina, definición de Paul Celan, para establecer la posibilidad de una traducción en el arte o perteneciente al proceso artístico, el de Doris Salcedo. El diálogo no es solamente una idea esencial de la poética de Celan y de la propuesta artística de Salcedo, es igualmente aquel que se teje entre los dos y se revela como fundamento de la creación estética. En suma, este texto aborda la traducción como proceso destinado a ilustrar la discusión estética.

Un dialogo así concebido, entre un poeta como Paul Celan y una artista como Doris Salcedo, no es posible sino dentro de una investigación estética. Pasar por la experiencia de los lenguajes del arte y de las lenguas naturales permite tener esa otra mirada sobre los criterios de la obras y sobre el análisis que estos permiten hacer. Un lugar para pensar las conexiones del arte colombiano desde una perspectiva más amplia y en diálogo constante con el arte y la literatura europea.

\section{TOMAR POSICIÓN: ESCULPIR}

En 1990, la artista colombiana Doris Salcedo presentó una exposición en la Galería Garcés Velásquez de Bogotá (figura 1). A lo largo de un espacio vacío se ubicaron algunas columnas de camisas blancas, atravesadas, cada una en su centro, por varillas de acero. Al lado, el espectador encontraba rejas de hierro de camas de hospital, atravesadas también por fibras de origen animal. Esta obra de la artista marca el inicio de un trabajo más a profundidad sobre la noción de espacio en escultura, la reflexión sobre la temporalidad de la materia y de la obra como lugar de memoria.

El cemento de las columnas de las camisas blancas - reunidas por grupos de número diferentes - es imperceptible o invisible. En efecto, todas las camisas han sido 
almidonadas con cemento, pero parecen tan limpias, ordenadas y arregladas en sus columnas que en un periodo breve no podemos apreciarlas, sino que solo una contemplación durable nos permitirá darnos cuenta de los materiales utilizados y de sus propósitos.

La serie Untitled (figura 2), realizada entre 1989 y 1995, presenta objetos (camas, armarios, sillas) que han sido parte del mobiliario personal o privado de una casa, pero que han sido previamente producidos en serie e industrialmente. Estos objetos en madera han sido también recubiertos con cemento. Como tejidos o digeridos por el cemento, el espectador puede percibir pedazos de tela, de vidrio y de acero.

Hoy en día, la descripción de unas esculturas como estas no nos asombra tanto. Desde hace más de sesenta años, los artistas han comenzado a "llamar esculturas las cosas más diversas", afirma Rosalind Krauss (1993, p. 113). El espacio sólido, eterno y monumental de la escultura ha sido excavado, desplazado y removido. "Hacia finales de los años sesenta, cuando la 'escultura' ha comenzado a aparecer bajo la forma de montones de relleno de hilos puestos sobre el suelo, pedazos de troncos de secuoya rodando al interior de una galería, toneladas de tierra arrancadas del desierto, empalizadas en troncos rodeadas de canales, se ha vuelto relativamente más embarazoso pronunciar la palabra 'escultura'"' (Krauss, 1992, p. 113).

En una nueva serie de esculturas realizadas entre 1992 y 1993, la artista introduce otros materiales aún más efímeros. Se trata de Atrabiliarios $^{1}$ (figura 3), nichos colgados en

1 "La palabra Atrabiliarios viene del latín y significa la melancolía asociada al duelo. Atra bilis viene de atratus que significa: vestirse de
Figura 1. Doris Salcedo, Untitled (1990). Acero, tela (camisas blancas), cemento.

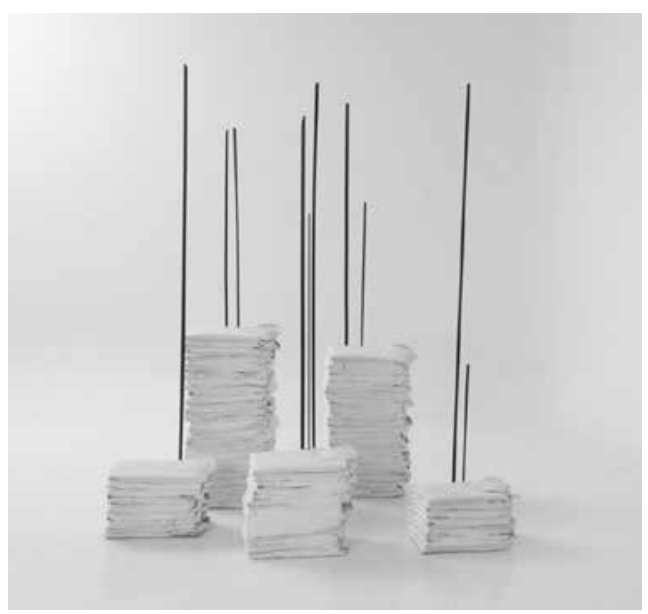

Fuente: Museo Thyssen Bornemisza, 2009

Figura 2. Doris Salcedo, Untitled (1989-1995). Madera, acero, cemento, vidrio y tela.

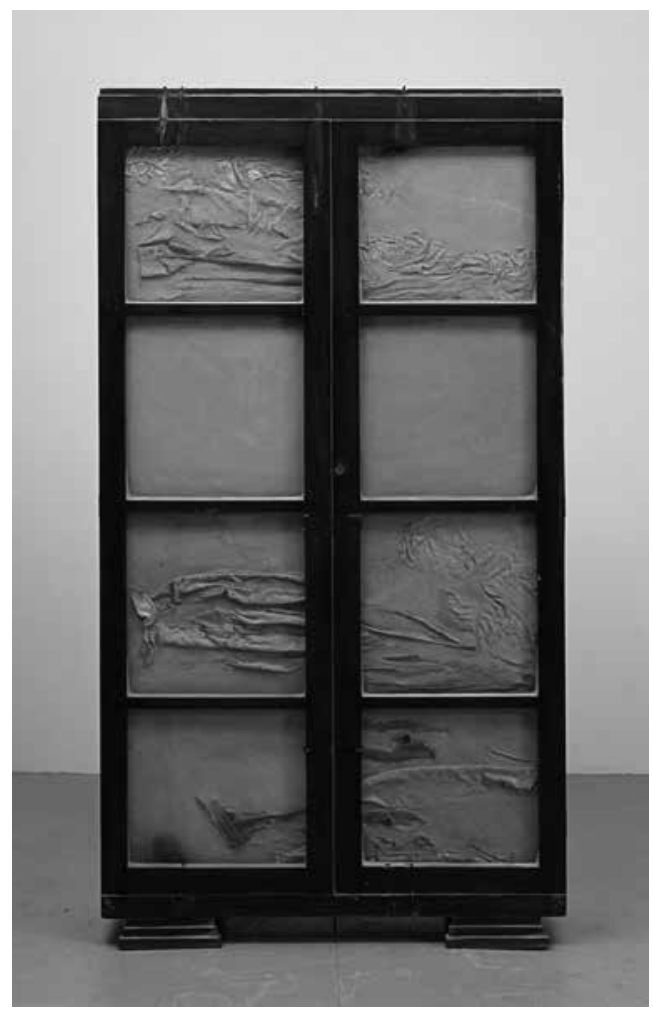

Fuente: Museum of Contemporary Art Chicago, 2015 
la pared como si fueran pinturas, fabricados en vejiga de vaca y en piel, encerrando zapatos. El zapato o los pares de zapatos están también protegidos por fibras extraídas de órganos internos de los animales. Si nos acercamos a buscar el detalle, descubrimos que esta fibra está tejida con el hilo utilizado en cirugía, y que su aparente transparencia no deja ver sino una parte del objeto situado atrás. Vemos también que los zapatos han sido utilizados, que estos pertenecían a alguien desconocido para el observador, alguien ausente. La persona que ha utilizado los zapatos ha desaparecido, en algunos casos por la fuerza, como lo sugieren o testimonian los zapatos sin su par.

Es precisamente esta ausencia la que va a definir la especificidad del objeto esculpido. Entre 1992 y 1995, la artista se dirigió a los hogares de las viudas y viudos de la violencia en Colombia, personas que contaban la historia de su compañero/a desaparecido/a y la experiencia de su vida cotidiana entre la ausencia y la esperanza de reencontrarlos. Después de la desaparición de la persona amada, ¿qué hacemos con su silla, con su armario, con su cama?

Detrás de cada una de las obras de Salcedo existe, tejido entre los materiales, en la experiencia de fabricación y de contemplación, un relato. El primer relato es la palabra del otro, pero no es una palabra que busca ahondar en el dolor para mostrar el lado mórbido de la desaparición y de la ausencia. La artista se encuentra con las víctimas de la violencia para hablar con ellas. No se trata de una entrevista, sino más que todo de un diálogo.

negro en duelo; y bilis significa la rabia, ira, la cólera" (Princenthal, 2001, pp. 51-54).
Figura 3. Doris Salcedo, Atrabiliarios (1992-1993), zapatos, madera, fibra animal, hilo.

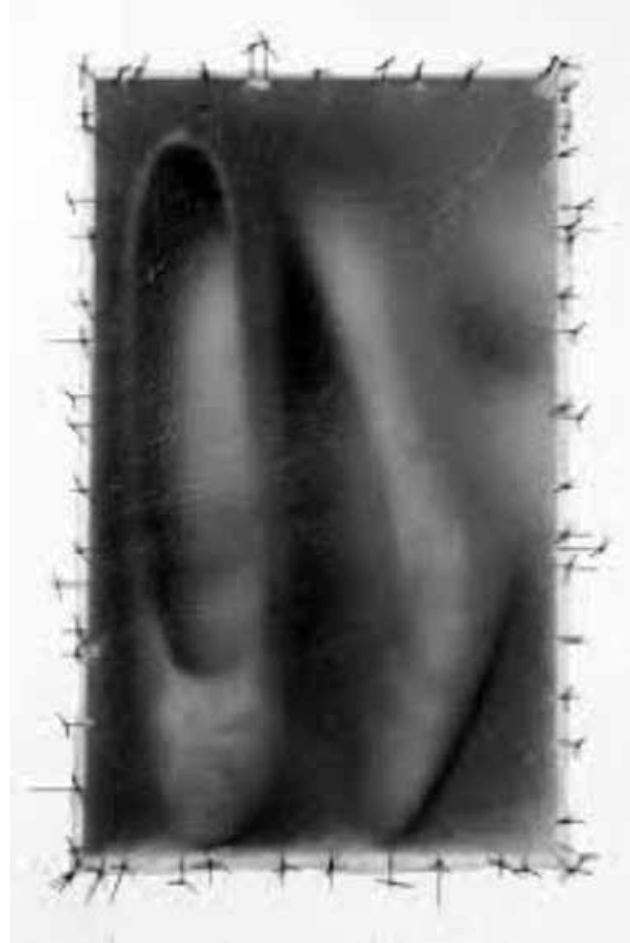

Fuente: Ministerio de Educación, Cultura y Deporte, Gobierno de España, 2015

El segundo relato es el del objeto. En la historia que cuentan las víctimas de la violencia, Salcedo encuentra varias referencias a los objetos que le pertenecían a la persona desaparecida. En medio de su necesidad de describir al otro, la víctima lo relata desde los objetos que poseía y la manera como los utilizaba.

La artista toma el objeto: armarios, camas o sillas. Los objetos están, de ahora en adelante, vacíos y gritan la ausencia de su utilizador. Salcedo se da cuenta de que si la persona no está más allí, el objeto se vuelve obsoleto, inútil, no-funcional; pero eso que le interesa a la artista es la capacidad que tiene este objeto de recordar. 
El tercer relato será el del espectador. Este va a sentir el silencio de la obra, el silencio y la herida del objeto, los dos elementos que, según Salcedo, transmiten eso que es común en todos los hombres.

La serie La casa viuda, 1992-1995 es, en relación con el primer relato, la historia de las viudas y viudos que han perdido a su ser querido. La parte más importante de este relato es el trauma. En todo acto doloroso o violento existe un momento de incomprensión en el que los sentidos no son capaces de hacer una distinción temporal de los eventos. El crítico Andreas Huyssen (2001), hablando de la obra de Salcedo, hace referencia al trauma. Afirma que el acto violento no llega dentro del continuum normal de la experiencia. El tiempo, el espacio y la causalidad dejan de ser objetivos; el acto es una ruptura de la continuidad de la vida. El trauma es entonces un suceso que no tiene ni antes, ni después, ni origen, ni fin. El problema se encuentra en la reconstrucción de los sucesos, porque la memoria no puede ligar los recuerdos secuencialmente. Algunas veces las víctimas se expresan a partir de objetos o de acciones repetitivas y no tanto por medio de las palabras. El problema, concluye Huyssen, es que el acto violento permanece abierto y se expone siempre como una herida (2001).

La artista es consciente de que el espectador no tiene ninguna relación con la víctima $\mathrm{y}$ que la historia de una víctima es muy similar a la de tantas otras. Por consiguiente, la obra artística de Salcedo consiste en modificar la condición de la víctima y de la herida para que esta sea escuchada y sentida. Según Salcedo, la obra debe ser la evidencia de la vida, pero del estado de la víctima, es decir, se trata de sobrevivir. Los materiales también están heridos, desviados y, como ya lo hemos visto, mezclados con telas, cabellos y huesos. Los materiales se descomponen, porque es su manera de afirmar que son tan precarios como la vida. En las salas de exposición de las series Untitled y La casa viuda, las presencias sólidas se erigen dejando espacios vacíos entre un objeto y otro. Las puertas se caen sobre las paredes, e impiden así el paso; una silla está incrustada en una puerta sobre el piso y un taburete emerge de otra.

La obra de las camisas atravesadas por varas de acero es el producto de un relato. Se trata de un suceso histórico, una masacre de la que nadie se acuerda, según la artista, porque la memoria es muy frágil en estos casos. Ella no representa figurativamente el secuestro, ni los campesinos asesinados. Son camisas blancas almidonadas con cemento, atravesadas en "pleno corazón" por varas de acero, que cumplen el papel de activar la memoria colectiva.

La poesía de Paul Celan evoca de manera profunda este duelo y un paso semejante de la voz del lenguaje, o más precisamente de la sombra del lenguaje hacia la apertura del espacio del silencio, como lo testimonia este poema que hace parte del libro Cambio de aliento.

Tenerse, a la sombra

del estigma de las heridas en el aire.

Tenerse, por nadie ni por nada,

incógnito,

por ti

solo

Con todo lo que hay aquí de espacio, también sin

lenguaje (1999, p. 211). 
Este poema ha sido además citado varias veces por la artista Doris Salcedo en sus obras de la serie Untitled. Uniendo la voz de Doris Salcedo y la de Paul Celan, podemos decir que los objetos del mobiliario hechos símbolos se sostienen en pie en su propia herida como objetos y como memoria, al mismo tiempo que abren el espacio del silencio.

\section{LUGAR DE ENCUENTRO Y TRANSPOSICIÓN}

Entre las obras de Salcedo y la poética de Paul Celan existen ciertas afinidades que nos permiten abordar el tema de la traducción en el ejercicio mismo de la creación artística. Salcedo ha afirmado constantemente que su trabajo depende también de las lecturas de filósofos y de poetas que le dan más peso a sus esculturas. Este peso es el de la historia humana, de la reflexión sobre el hombre y sobre el lenguaje, preocupación que comparte con Paul Celan, a quien cita constantemente en sus obras y entrevistas.

La artista Doris Salcedo afirma que el interés que ella le da al espacio en escultura viene de la idea de que este "es una especie de cruce de avenidas, un lugar de encuentro, que hace posible la vida" (Bausaldo, 2001, p. 11). En esa medida, el espacio debe estar constantemente en relación o en movimiento. El espacio es para Doris Salcedo la evidencia de la posición en la que ella se encuentra, a partir de la cual el hombre piensa, observa, habla.

Para Celan el poema es un hablar fundado en un siempre-todavía: "Este siempre-todavía se descubre en el solo poema de aquel que no olvida hablar en el ángulo de inclinación de su existencia, en el ángulo de inclinación donde la creatura se enuncia" (Celan, 2008, p. 3). El ángulo de inclinación de la existencia y de enunciación es la posición del poeta. La cuestión es, entonces, ética, el poema se ofrece como poeta: "quien lo traza permanece a él dedicado", escribe el poeta en El Meridiano. La noción de posición en Celan es esencial para comprender el valor del diálogo de su poesía y la importancia que le otorga a la toma de consciencia de sí mismo. El poema es el destino del poeta.

La posición es la pausa que el hombre o el objeto hacen para que el espacio se vuelva lugar de encuentro, una apertura de caminos, una posibilidad de fundar la vida en el movimiento de la cotidianidad. La posición es la pausa necesaria para que el hombre pueda reflexionar sobre sí mismo, pensarse y pensar la lengua que le da sentido.

Ahora bien, la transposición es un concepto difícil de definir porque se emplea de una manera específica en ciertas disciplinas como la música, la mineralogía o las matemáticas. El concepto aparece en esta investigación cuando la artista Doris Salcedo afirma que su trabajo es un trabajo de transposición. En español, el término nos acerca al discurso de la semiología. La transposición, según el semiólogo argentino Oscar Steimberg (1998), es el pasaje de una obra literaria a un registro diferente como el cine, el cómic o las series de televisión. Sin embargo, es la etimología de esta palabra la que mejor nos indica el camino.

La transposición y el verbo en español transponer vienen del latín transponere que denota la acción “de poner a alguien o alguna cosa más allá o un en un lugar diferente de aquel que ocupaba". Significa también 
“adaptar una situación o una condición en otro contexto cambiando su forma; es una inversión en la construcción ordinaria de las palabras" ${ }^{\prime 2}$. Al unir las definiciones arriba presentadas, diríamos que la transposición significa el desplazamiento de un objeto, de una persona, de una palabra, pero también de una situación o de una condición hacia un lugar o contexto diferentes, cambiando su forma. De esta manera, la definición se hace más compleja, pero el sentido de la palabra no se limita solamente a un cambio de lugar.

La obra Unland: the orphan's tunic (figura 4) fue presentada por primera vez en el New Museum of Contemporary Art de Nueva York en 1998. Esta es la primera de las tres obras que hacen parte de la serie Unland. El título viene de la poesía de Paul Celan y es un neologismo en alemán, y podemos leerlo como la ausencia o la negación (un) del territorio (land). La obra está compuesta por dos mesas de madera, las dos tienen una altura diferente, apenas perceptible. Las dos mesas están incrustadas en su centro. Si nos acercamos a la obra, vemos que la superficie de las dos ha sido tejida con cabellos negros, formando una especie de piel, y que una delgada tela de seda tejida hace la transición entre las dos mesas desiguales.

La segunda obra de la serie, titulada Unland: irreversible witness, es una cama de niño incrustada en una mesa, tejida también con cabellos negros y con seda. La tercera obra es Unland: audible in the mouth; son dos mesas de la misma altura, la transición entre ellas se hace también con cabellos y con seda, pero de forma cada vez más sutil.

2 Las definiciones provienen del Diccionario de la Real Academia de la Lengua Española.
Figura 4. Doris Salcedo, Unland: the orphan's tunic (2004), madera, seda, cabellos. Propiedad de la Fundación la Caixa, Barcelona. Instalación, Tate Modern, Londres.

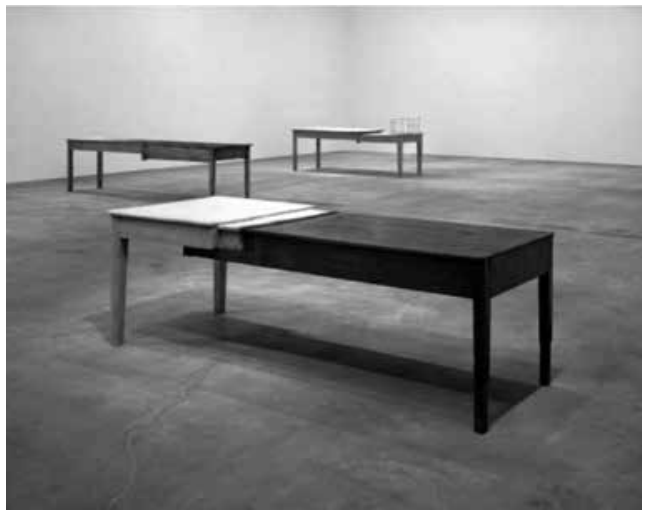

Fuente: Art21, 2015

Un poema de Paul Celan es citado con la obra; hace parte del libro Compulsión de luz, publicado en 1970 después de la muerte del poeta. El poema toma el lugar del testimonio.

Lo arrebató el caballo de la noche, había vuelto a sí mismo,

El blusón de huérfano por bandera,

Ya no hubo extravíos,

Lo arrebató por derecho.

Es,

es como si estuviera en el aligustre de las naranjas

como si el así arrebatado no llevara puesto

más que su

primera

piel

maternal de lunares, estelar de misterio (1999, p. 213).

Ya habíamos dicho que todas las obras de Salcedo son el producto de un diálogo con las víctimas, que este diálogo está siempre 
ausente, pero que aparece y se difunde en la obra bajo diferentes formas: Es transformado. El objetivo del diálogo es dejar a las víctimas hablar para que la artista pueda convertirse ella misma en una víctima. Ella debe cambiar su lugar con la víctima, tomar su lugar, para ser capaz de sentir, en principio, el dolor. La víctima cuenta los sucesos, la experiencia, los recuerdos de una fecha. Esta fecha, que parece ser singular y personal, no es más que la evidencia de alguna cosa que se repite en la necesidad de mostrarse siempre-todavía, para retomar las palabras de Paul Celan. Cada escultura es la memoria de la presencia de eso que se repite, incluso si ya no está. La importancia no es recordarle al espectador la fecha del suceso que esta conmemora o el diálogo y las palabras que fueron intercambiadas, sino transponer la fecha para que esta sea el lugar sin lugar de la activación de la memoria colectiva.

En Celan, la fecha ejerce el mismo poder que en la escultura de Doris Salcedo. La fecha del simple suceso personal se transforma en poema "el poema le habla a todos, al otro, a quien sea que no comparta la experiencia" (Derrida, 1986, p. 21). Dicho de otra manera, el poema se convierte en el testigo que conmemora la fecha de la ausencia:

Para hablar de ella, debemos también borrarla, hacerla legible, audible, inteligible más allá de la pura singularidad de la que ella habla. Ahora bien, el más allá de la singularidad absoluta, la oportunidad para la exclamación del poema, no es simplemente borrar la fecha en una generalidad, es su borramiento delante de otra fecha, aquella a la que ella habla, la fecha de otro o de otra que se alía extrañamente, en el secreto de un encuentro, un secreto de encuentro, con la misma fecha (Derrida, 1986, p. 23).

Con el poeta planteamos nuevamente la pregunta: “¿Nosotros mismos, para qué fechas, a venir, nos transcribiremos?" (Celan, 2008, p. 30).

Paralelamente, la tarea de Salcedo es hacer el objeto inutilizable, marcar la ausencia en la piel del objeto, para que esta sea evidente. El objeto se vuelve el doble testigo: por una parte, de la ausencia de una persona $y$, por otra, de la transposición del diálogo en trabajo artístico sufrido por la artista. La obra se hace frágil y vulnerable por la utilización de materiales precarios, por el encuentro de dos o más materiales incongruentes que van a terminar por destruir la obra; pero sobre todo la acción de anudar - los finos cabellos y las telas - y el cuidado que esto demanda. Finalmente, es el objeto que se presenta como testigo, que se expone como herida. Dicho de otra manera, la fecha se transforma en persona ausente y en la negación de la persona misma.

Barrido por

el mordiente del viento irradiante de tu lenguaje, el palabreo variopinto de lo propiamente-vivido - el Míopoema de cien bocas el Nada-poema..

[...]

Hondo en la grieta de los tiempos, junto al hielo panal espera, cristal de aliento, 
tu irrevocable

testimonio (1999, p. 214).

En Celan la transposición pasa por la lengua materna, "su poética se funda allí: darle sentido a la palabra (en alemán: aclararla), es ahondar su nada, 'dar su sombra'" (Lefebvre, 1998, p. 10); es decir, poner en distancia su lengua materna para traducirla o doblarla en ella misma. El poeta siendo al interior del lenguaje, para que este comenzara a decir lo que debe decir, para que la lengua comience a hablar lo no-dicho. El ejemplo de este redoblamiento es el recurso a los neologismos, a los cambios de significación de las palabras, a las palabras de un vocabulario técnico sacado de diferentes disciplinas, a las conjugaciones verbales. Las palabras ya no significan lo que significaban antes. "Redoblada la lengua se hace diálogo, y un 'Tú' y un 'Yo' se despiertan [...] tal vez también en ese juego entre las dos lenguas que es la traducción" (Broda, 1986, p. 72). La traducción se hace en el interior de la misma lengua alemana, para que esta ya no pueda decir todo lo que dijo durante y después de la Segunda Guerra Mundial, y para que pueda comenzar a expresarse:

¿Qué pasó? la piedra salió de la montaña.

¿Quién despertó? Tú y yo.

Lengua, lengua. Constelación. Tierra cercana.

Más pobre. Abierta. Natal.

¿Adónde iba esto? a lo no del todo sonado.

Con nosotros dos, con la piedra iba esto.

Corazón y corazón. Pareció demasiado pesado.
Volverse más pesado. Ser más ligero (1999, p. 187).

El lenguaje de Celan es una interrupción de la mímesis porque "el acto poético consiste en percibir, no en representar" (Broda, 1986, p. 99). Esta interrupción requiere tropos que no pertenecen más a la mímesis, sino al lenguaje del encuentro, de la percepción. Paul Celan ha puesto en distancia la palabra de la palabra misma, para arrancarle su peso conceptual. Él funda así la contra-palabra. Esta contra-palabra es la ruptura de la mímesis que le da al poema el carácter de contratiempo, de un tiempo fuera de la historicidad que le permitirá fundar lugares de encuentro con un presente, pero desde un pasado siempre en devenir.

Marcado por la fecha y el lugar, la palabra es una impresión en la materia. La plasticidad transpuesta de la lengua dialogada es la evidencia del abismo del pensamiento. Ya habíamos señalado que el lenguaje de la víctima es traumático, es decir, que no tiene coherencia secuencial y que sus recuerdos son vagos. Podemos agregar que el lenguaje se manifiesta como si este se encontrara en un estado naciente de la lengua, del pensamiento. El objeto esculpido se forma en la transposición del trauma del lenguaje hacia la herida física, de la piel del hombre ausente, pero in-visible en la materia, y del artista durante el proceso de creación. La materia misma, con su facultad de recordar, nos muestra el espacio vacío del encuentro. La obra Unland es finalmente una pérdida de lugar.

La transposición o cambio de forma, en el desplazamiento de un objeto, de alguien o de la palabra hacia otro lugar, es inherente al proceso creativo o el proceso de dar forma. 


\section{El diÁlogo QUE SE ENCAMINA}

\section{El traduce de leído a vivo. Paul Celan}

La transposición no es más que el origen de la traducción, al igual que su sinónimo. Sin embargo, esta transposición-traducción comprende una connotación más radical en el sentido que el poeta y el artista son transpuestos ellos mismos hacia un estado otro que va a producir la obra. Y, de una cierta manera, el espectador está invitado a transponerse en esta experiencia. Así la obra de estos dos artistas tiene un carácter dialógico.

Jean-Pierre Lefebvre en el prefacio de Poemas escogidos afirma: "la traducción no es para Celan una operación de transferencia pura y simple, un asunto de un pasante que retorna a su lado, sino un "diálogo que se encamina", y en esta definición se une a su poesía [...]" (1998, p. 23). Paul Celan fue poeta y traductor, pero sus traducciones comparten casi el mismo estatus que su poesía. Las traducciones de Celan eran también encuentros, testimonios del trabajo sobre la lengua: ese lugar de encuentro que es la traducción.

Según Borges, la fidelidad o la originalidad no tienen nada que ver con la traducción, porque el verdadero problema de la traducción es descubrir cómo esta transforma una obra y revela sus aspectos de composición, de lectura, de interpretación. Borges concebía la traducción como el modus operandi de la creación literaria, reveladora de una estética.

Los poemas de Paul Celan, según Philippe Lacoue-Labarthe (1986), son traducciones de eso que dice como poema, es decir, de una experiencia. El origen de la palabra "experiencia" viene del latín experiri que significa atravesar un peligro. "Yo digo experiencia porque es allí donde "florece" el poema, aquí - la memoria de un deslumbramiento, es decir, el puro vértigo de la memoria-, es justamente eso que no ha tenido lugar, que no ha llegado o advenido durante el suceso singular al cual el poema se refiere, y al que no se refiere" (Lacoue-Labarthe, 1986, pp. 30, 31). Esta definición establece una relación con el lenguaje traumático, del que ya hemos hablado, y que Lacoue-Labarthe califica como vértigo. Así, el poema no nace en el suceso, tampoco es el relato del suceso, él no nace propiamente en ningún instante. El poema es la traducción de la experiencia de un lugar sin lugar del vértigo de la memoria; pero, ¿de cuál memoria?

Algunos reparos de la vida de Paul Celan son necesarios en este momento para comprender la importancia de la experiencia. Paul Celan, judío de lengua materna alemana, pasa la época de su infancia entre los sucesos que van a marcar su vida personal y su creación poética. Ellos son principalmente el Holocausto, la Segunda Guerra Mundial y la muerte de sus padres y de sus amigos. Se trata de su posición como víctima, pero también como testigo de las acciones del hombre: "La ignominia sin precedente de la que fue $-y$ permanece - culpable la “época del sujeto'" (Lacoue-Labarthe, 1986, p. 24).

Paralelamente, Doris Salcedo es el testigo de la narración de las víctimas, de la palabra viva de la experiencia de otros, pero ella es también el testigo de la violencia del país en el que habita. Los dos artistas son eso que Walter Benjamin denominaba el narrador: la narración "no busca transmitir la cosa 
desnuda en ella misma como un reporte o una información. Ella asimila la cosa a la vida misma de aquel que la cuenta para luego recuperarla de nuevo en él. Así adhiere a la narración la huella del narrador como una vasija de arcilla la huella de la mano del artesano" (1991, p. 275). La idea de asimilar la cosa significa que los artistas se funden en ella, con todo el dolor que esta implica, para mantener la huella de la vida del otro, para que ella permanezca viva por la narración.

Benjamin agrega que "eso que el narrador cuenta, lo tiene como experiencia, de la suya propia o de una experiencia comunicada. Y a su vez la hace la experiencia de aquellos que escuchan su historia" (1991, p. 272). El encuentro está, en este caso, ligado al lector o al espectador posible de la obra. El "atravesar el peligro" en Salcedo ${ }^{3}$ connota principalmente la transposición del trauma y de la herida, para que la artista pueda probar el sufrimiento, luego para que los espectadores hagan el duelo colectivo. La narración permite a la obra de Salcedo transponerse en el espectador, con el fin de que este pueda sufrir la experiencia de atravesar el peligro.

La transposición está unida también al verbo desplazar. El desplazamiento, en su connotación política y social, es la acción de hacer mover una comunidad, un grupo humano de un territorio a otro, por medio de fuerzas dominantes que comandan la transferencia. Paul Celan ha tenido esa experiencia. El poeta Paul Celan se desplazó durante la mayor parte de su vida de un

3 A lo largo de una entrevista para televisión, la artista Doris Salcedo afirma que ella ha trabajado el concepto de experiencia desde su etimología, que significa el atravesar un peligro. Ver en Doris Salcedo, third world identity, artículo 21, http://www.youtube.com/ watch? $\mathrm{v}=\mathrm{dwp}$ iFBdSCrO\&feature=related lugar a otro, de un país a otro. Este desplazamiento, que la mayor parte del tiempo lo hizo por obligación, implica un cambio de posición para pensarse a sí mismo y comprender el mundo. Este cambio de posición implica el aprendizaje de otras lenguas, el trabajo de la traducción, incluida la lengua materna. Doris Salcedo no ha vivido jamás algo similar, pero ella afirma que habita en Colombia como un testigo. Ella ha decidido tomar distancia con el fin de adoptar una posición crítica para poder desarrollar su trabajo plástico. "Cuando regresé a Colombia, continué viviendo como una extranjera, porque eso me ha dado la distancia de la que necesitaba para ser crítica frente a la sociedad a la cual pertenecía" (Bausaldo, 2001, p. 9). Esta distancia es reflexiva: es la posibilidad de tomar una posición y de hablar un lenguaje, con la capacidad de comprender ese lenguaje, sabiendo que es uno en medio de otros.

Así, el desplazamiento de la lengua, pero también del sujeto, permite al exilio tomar un valor más positivo, aquel del retorno necesario, salir de sí, como lo precisa Martine Broda (1986). El diálogo no es posible sino en el exilio: este permite al individuo dividirse, $\mathrm{y}$ a la lengua conversar fuera de ella misma.

Con el análisis de la obra Shibboleth de Doris Salcedo y el análisis del sentido de "schibboleth" en la poesía de Paul Celan, veremos cómo se hace evidente eso que debemos traducir. Se trata de saber cómo Doris Salcedo ha puesto en diálogo la lengua de Paul Celan con su propia lengua a partir de la traducción.

Notemos que las dos palabras no son iguales. La palabra "schibboleth" ha sido traducida al español sin la letra " $c$ ". Las razones 
son fonéticas: en español no existen palabras que comiencen por la unión de las letras "sch", lo que haría la palabra impronunciable. La escogencia es ciertamente del traductor ${ }^{4}$, que tal vez ha decidido hacer alusión a la historia del origen de la palabra. La transcribimos aquí en palabras de Jacques Derrida:

Schibboleth [...] ha tomado el valor de una contraseña. Se utilizó, durante o después de la guerra, al pasar una frontera vigilada. La palabra importaba menos por su sentido que por la manera en la que ésta era pronunciada. La relación con el sentido o con la cosa se encontraba suspendida, neutralizada, puesta entre paréntesis. [...] Los efraimitas habían sido vencidos por el ejército de Jefté; y para impedir que los soldados se escaparan pasando el río [...], se requería que cada persona dijera schibboleth. Ahora bien, los efraimitas eran conocidos por su incapacidad para pronunciar correctamente la schi de schibbolleth que se volvía para ellos una palabra impronunciable. Ellos decían sibboleth $\mathrm{y}$, sobre esta frontera invisible entre schi y si, denunciaban su diferencia haciéndose indiferentes a la diferencia diacrítica entre schi y si; se marcaban al no poder re-marcar una marca así codificada (1986, pp. 44, 45).

La obra Shibboleth de Doris Salcedo es un hueco de 167 metros instalado en la Turbine Hall de la Tate Modern en Londres en 2007 (figura 5). Este hueco está recubierto de rejas de hierro, que solo son visibles si

4 Otras traducciones en español marcan el acento en la "o" de Shibbólet para mostrar cómo debe ser pronunciada, y le quitan la "h" final que en ese lugar de la palabra no produce ningún sonido.
Figura 5. Doris Salcedo, Shibboleth, 2007. Tate Modern, Londres.

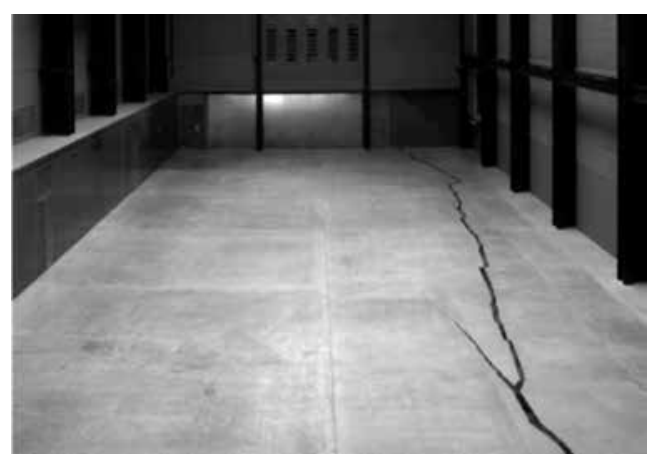

Fuente: Art21, 2015

nos acercamos y miramos en su interior. Las rejas de hierro son el material utilizado generalmente para separar, demarcar, para excluir. Esta escultura subterránea fue hecha en Colombia, los muros que la componen son colombianos, pero las rejas de hierro son las mismas que se utilizan para delimitar la única frontera terrestre entre Europa y el Tercer Mundo en Ceuta y Melilla en África. Todas las piezas de la escultura fueron construidas en el taller de Salcedo en Bogotá. Luego, viajaron en barco hasta llegar a Londres.

Este hueco rompe ciertos elementos: primero la estructura misma de la Galería, su estabilidad. Unido a la idea de escindir físicamente la galería, la obra rompe otros elementos que la galería representa; por ejemplo, la institución del arte en relación con el canon occidental, los límites entre los diferentes lados: la nacionalidad, la raza, el género.

Pero, ¿por qué la palabra "schibboleth" se ha convertido en un hueco?, ¿qué es lo que no ha podido cicatrizar? Vamos a intentar responder estas preguntas, citando también el poema de Paul Celan Schibboleth, que pertenece al libro De umbral en umbral. 
Según Derrida "Schibboleth marca la multiplicidad en la lengua, la diferencia insignificante como condición del sentido" (1986, p. 54). La diferencia insignificante es la de la pronunciación. La pronunciación de la palabra se vuelve discriminante, decisiva y cortante. Primer sentido metafórico de la fisura, del hueco.

Junto con mis piedras, crecidas en el llanto detrás de las rejas, (1999, p. 106).

Según el análisis de Maurice Blanchot (1984), hablar sería tenerse detrás de la reja, aquella de las prisiones a través de las cuales se promete, se rechaza, la libertad del afuera. Pero también esta "reja de lenguaje" sugiere la dificultad de hablarle al otro. Podemos agregar que esta dificultad comienza por la pronunciación de esta palabra de paso, esta palabra que da el acceso. "Esta diferencia no tiene ningún sentido por ella misma, pero se convierte en eso que hay que saber reconocer y sobre todo marcar para hacer el paso, para pasar la frontera de un lugar o de un umbral de un poema, hacerse otorgar un derecho de asilo o una habitación legítima de una lengua. Para no estar más fuera de la ley" (Derrida, 1986, p. 50). Aquí está el segundo sentido de la fisura: ella es el derecho al paso acordado a aquellos que pertenecen a esta o aquella comunidad.

me arrastraron

al centro del mercado,

allí

donde se despliega la bandera, a la que no presté juramento (1999, p. 106).

Los materiales utilizados en la obra juegan también su rol, en razón del lugar del que provienen. El hueco del museo es una línea de la demarcación entre los unos y los otros. Es sinónimo de racismo, de segregación. La reja de hierro nos impide penetrar, atravesar el hueco. La reja no deja ninguna esperanza.

Flauta,

flauta doble de la noche:

piensa en la oscura

aurora gemela

en Viena y Madrid.

Pon tu bandera a media asta, memoria.

A media asta

hoy para siempre.

Corazón:

date a conocer también

aquí, en medio del mercado.

Di a voces el schibboleth

en lo extranjero de la patria:

Febrero, no pasarán (1999, p. 107).

Pero el schibboleth es también el derecho a la vida que otros se han tomado por su cuenta. El tercer sentido de la fisura sería la exclusión, la violencia y la muerte. En otros términos: corte, lugar de pasaje y derecho a la vida.

Einhorn:

tú sabes de las piedras,

tú sabes de las aguas,

ven,

yo te llevaré lejos,

a las voces

de Extremadura (1999, p. 107).

No podemos afirmar que el tema del poema es el racismo, como lo indica Doris Salcedo en referencia a su obra. Para ella, eso es lo que no puede cicatrizar; la reja simboliza el desespero de terminar un día con el 
racismo. Por el contrario, el poema de Celan nos mantiene en la esperanza y la lucha por el derecho a la vida. Ahora bien, eso que debe ser traducido es el discurso de la permanencia de la violencia, sobre todo del racismo. Actualmente, las formas de aniquilación son diferentes. Estas comienzan por la discriminación, el rechazo del derecho de pertenecer a un país, a un tipo de sociedad, a una religión o a un grupo.

Los enemigos cambian, las formas de aniquilación cambian, las armas cambian, pero la naturaleza de la guerra sigue siendo la misma. Cuando yo hablo de Colombia, es porque es la realidad que mejor conozco. Yo no hablo de la violencia en Colombia desde un punto de vista nacionalista. [...] Además, la violencia está presente en el mundo entero y en todos los seres. [...] La crueldad, la indolencia y el odio hacia el otro son universales. Yo busco la posibilidad de hacer la conexión entre el suceso particular y severo que ha ocurrido en Colombia y en un suceso parecido, cruel y severo, que ocurre todos los días en otro lado (Princenthal, 2001, p. 142).

La obra de Doris Salcedo actualiza el debate: la obra habla desde el lenguaje de la escultura contemporánea y ella deja una huella, una herida.

La obra de Doris Salcedo, Shibboleth, devela cómo un discurso enunciado puede volverse un discurso que permanece todavía por decirse. Esta traducción es posible cuando el artista comprende el sentido de la experiencia, del desplazamiento y del exilio. El diálogo significa basar la experiencia en el encuentro.
La traducción de Paul Celan por Doris Salcedo se vuelve evidente por la forma plástica que ella crea. Borges (1996) afirma que la traducción muestra cómo la idea de una literatura nacional es estéril y reductora, porque lo esencial es convertir la traducción en un hecho artístico capaz de hacer historia. En el mismo orden de ideas, Henri Meschonnic (1999) observa que si la tarea de un traductor es reducir todas las lenguas a la propia, todos los discursos al suyo, esta terminará siendo un monstruo. La traducción de una obra extranjera, por el contrario, muestra cómo se hace la transposición de la lengua, por la huella que deja esta lengua de todo lo que tiene de tradición, de pensamiento, de cultura. En suma, la traducción muestra la diferencia, debe asegurar la apertura de espacios sintácticos, de las múltiples formas que puede tomar la obra, de las relaciones culturales e históricas. La traducción revela los aspectos de composición, ella es reveladora de una estética.

\section{LA TRADUCCIÓN ILUSTRA LA DISCUSIÓN ESTÉTICA}

Los dos últimos ejemplos presentados, la obra Shibboleth y la obra Unland revelan eso que Jorge Luis Borges afirmaba en relación con la traducción: las obras muestran que existe un obstáculo insalvable entre el poeta - eso que Celan se representaba escribiendo sus poemas - y la idea de la fidelidad al original en la traducción; pero muestran también que es posible tener lecturas siempre diversas y traducciones divergentes. En efecto, una traducción así concebida deja ver cómo un lenguaje como la poesía se ve transpuesto en una obra plástica, que pertenece al contexto de la escultura contemporánea y a otra discusión estética. Los 
dos son lenguas extranjeras que dialogan entre ellas, pero que dialogando muestran, como lo decía Walter Benjamin, todas las mutaciones del lenguaje, de la época y del pensamiento.

Podemos también afirmar con Walter Benjamin en "La tarea del traductor" que lo buscado y la manera de lo buscado puede consistir en mostrar eso que siempre debe traducirse: el discurso que sostienen las obras y la diferencia de las lenguas. En efecto, se trata de mostrar cómo los lenguajes - la escultura y la poesía - buscan una misma realidad por medio de modos diferentes, pero que puede ser compartida en el diálogo, del cual se desprende la alteridad.

La posibilidad del diálogo en toda traducción habla de la importancia de salir de los límites identitarios de un lenguaje y de comenzar a pensar al otro a partir del exilio de sí mismo.

\section{ReFERENCIAS}

Art21 (2007). Doris Salcedo, third world identity. Recuperado de http://www.youtube.com/watch? $\mathrm{v}=\mathrm{d}$ wpiFBdSCr0\&feature=related

Art21 (2015). Doris Salcedo, Shibboleth, 2007. Tate Modern, Londres. Recuperado de http://www.art21.org/texts/ doris- salcedo/activity-questions-doris-sal cedo

Art21 (2015). Doris Salcedo, Unland: the orphan's tunic (2004). Tate Modern, Londres. Recuperado de http://www. art21.org/texts/doris-salcedo/activity -questions-doris-salcedo

Bausaldo, C. (2001). Carlos Basualdo in conversation with Doris Salcedo. En Doris Salcedo. Londres: Phaidon.
Benjamin, W. (1991). Le Narrateur. En Écrits français (pp. 272-275). Paris: Gallimard.

Benjamin, W. (2000). La tâche du traducteur. En CEuvres I. (pp.287-290). Paris: Gallimard.

Blanchot, M. (1984). Le dernier à parler. Paris: Fata Morgana.

Borges, J. L. (1996). Las versiones homéricas. En Obras completas I. (pp. 239-243). Argentina: Emecé.

Broda, M. (1986). Dans la main de personne. Essai sur Paul Celan. Paris: Les éditions du Cerf.

Celan, P. (2008). Le Méridien. Paris: Fata Morgana.

Celan, P. (1999). Paul Celan. Obras completas. España: Trotta.

Derrida, J. (1986). Schibboleth pour Paul Celan. Paris: Galilée.

González-Uribe, G. (marzo, abril, mayo, 2008). Doris Salcedo y Shibboleth. Una grieta en el corazón de Europa. Revista Número, 56, 62-75.

Huyssen, A. (2001). Focus, unland: the orphan's tunic. En Doris Salcedo. Londres: Phaidon.

Krauss, R. (1993). L'Originalité de l'avant-garde et autres mythes modernistes. Paris: Macula.

Lacoue-Labarthe, Ph. (1986). La poésie comme expérience. Paris: Christian Bourgeois éditeur.

Lefebvre, J.-P. (1998). Préface. En Choix de poèmes, réunis par l'auteur. Paris: Folio, Gallimard.

Ministerio de Edcuaciçon Cultura y Deporte, Gobierno de España. (2015). Doris Salcedo, Atrabiliarios (1992-1993). Recuperado de http://www.mecd.gob. es/cultura-mecd/en/areas-cultura/promociondelarte/premios/premio-velazquez/premiados/velazquez2010.html 
Museo Thyssen Bornemisza (2009). Doris Salcedo, Untitled (1990). Recuperado de http://www.museothyssen.org/thys sen/exposiciones_proximas/132

Museum of Contemporary Art Chicago (2015). Doris Salcedo, Untitled (1989-1995). Recuperado de http://www2.mcachicago.org/exhibition/doris-salcedo/
Meschonnic, H. (1999). Poétique du traduire. Paris : Éditions Verdier.

Princenthal, N. (2001). Survey. En Doris Salcedo. Londres: Phaidon.

Salcedo, D. (2007). TateShots Issue 8. Recuperado de http://www.youtube.com/ watch?v=NIJDn2MAn9I

Steimberg, O. (1998). Semiótica de los medios masivos. Buenos Aires: Atuel. 